\title{
Sulfur Dioxide Measurement
}

National Cancer Institute

\section{Source}

National Cancer Institute. Sulfur Dioxide Measurement. NCI Thesaurus. Code C114224.

The determination of the amount of sulfur dioxide present in a sample. 